\title{
Historical injustice in psychiatry with examples from Nazi Germany and others: ethical lessons for the modern professional Rael Strous
}

\author{
Address: Beer Yaakov Mental Health Center, Sackler Faculty of Medicine, Tel Aviv University, PO Box 1, Israel, 70350 Beer Yaakov, Israel \\ from WPA Thematic Conference. Coercive Treatment in Psychiatry: A Comprehensive Review \\ Dresden, Germany. 6-8 June 2007 \\ Published: 19 December 2007 \\ BMC Psychiatry 2007, 7(Suppl I):S93 doi:10.I I86/I47I-244X-7-SI-S93
}

This abstract is available from: http://www.biomedcentral.com/I47I-244X/7/SI/S93

(C) 2007 Strous; licensee BioMed Central Ltd.

For the first time in history, psychiatrists during the Nazi era sought to systematically exterminate their patients. However, little has been published from this dark period analyzing what may be learned for clinical and research psychiatry. At each stage in the murderous process lay a series of unethical and heinous practices with many psychiatrists demonstrating a profound commitment to the atrocities playing central, pivotal roles critical to the success of Nazi policy. Several misconceptions led to this misconduct including allowing philosophical constructs to define clinical practice, focusing exclusively on preventative medicine, allowing political pressures to influence practice, blurring roles of clinicians and researchers, and falsely believing that good science and good ethics always co-exist. Psychiatry during this period provides a most pervasive example of how science may be perverted by external politics. While the experience of psychiatry practice in Germany during the Nazi era is an extreme example, it is but one of a series of injustices that a small but prominent number of psychiatrists have perpetrated in history. It thus becomes crucial to include the Nazi era psychiatry experience as well as others, all be them of lesser scale and magnitude, in ethics training as an example of proper practice gone awry. 